\title{
Salvage brachytherapy in prostate local recurrence after radiation therapy: predicting factors for control and toxicity
}

Iván Henríquez ${ }^{1,4^{*}}$, Gemma Sancho ${ }^{2}$, Asunción Hervás ${ }^{3}$, Benjamin Guix ${ }^{4}$, Joan Pera ${ }^{5}$, Cristina Gutierrez ${ }^{5}$, Oscar Abuchaibe ${ }^{6}$, Rafael Martínez-Monge ${ }^{7}$, Alejandro Tormo ${ }^{8}$ and Alfredo Polo ${ }^{3}$

\begin{abstract}
Purpose: To evaluate efficacy and toxicity after salvage brachytherapy (BT) in prostate local recurrence after radiation therapy.

Methods and materials: Between 1993 and 2007, we retrospectively analyzed 56 consecutively patients (pts) undergoing salvage brachytherapy. After local biopsy-proven recurrence, pts received 145 Gy LDR-BT (37 pts, 66\%) or HDR-BT (19 pts, 34\%) in different dose levels according to biological equivalent doses $\left(B_{E} D_{2}\right.$ Gy $)$. By the time of salvage BT, only 15 pts (27\%) received ADT. Univariate and multivariate analyses were performed to identify predictors of biochemical control and toxicities. Acute and late genitourinary (GU) and gastrointestinal (Gl) toxicities were graded using Common Terminology Criteria for Adverse Events (CTCv3.0).
\end{abstract}

Results: Median follow-up after salvage BT was 48 months. The 5-year FFbF was 77\%. HDR and LDR late grade 3 GU toxicities were observed in $21 \%$ and $24 \%$. Late grade 3 Gl toxicities were observed in $2 \%$ (HDR) and 2.7\% (LDR). On univariate analysis, pre-salvage prostate-specific antigen $(P S A)>10 \mathrm{ng} / \mathrm{ml}(p=0.004)$, interval to relapse after initial treatment $<24$ months $(p=0.004)$ and salvage HDR-BT doses $B^{2} D_{2}$ gy level $<227$ Gy $(p=0.012)$ were significant in predicting biochemical failure. On Cox multivariate analysis, pre-salvage PSA, and time to relapse were significant in predicting biochemical failure.

HDR-BT BED 2 Gy ( $\alpha / \beta 1.5$ Gy) levels $\geq 227$ ( $p=0.013$ ), and ADT ( $p=0.049$ ) were significant in predicting grade $\geq 2$ urinary toxicity.

Conclusions: Prostate BT is an effective salvage modality in some selected prostate local recurrence patients after radiation therapy. Even, we provide some potential predictors of biochemical control and toxicity for prostate salvage BT, further investigation is recommended.

Keywords: Salvage brachytherapy, Prostate cancer, High-dose-rate-brachytherapy, Low-dose-rate-brachytherapy, Androgen deprivation therapy

\section{Introduction}

Patients with intermediate or high risk localized prostate cancer treated with standard dose radiation therapy with or without ADT have a 10 year-rate of biochemical failure $(\mathrm{BF})$ that ranges from $30 \%$ to $70 \%$. Some of these patients will die of prostate cancer [1].

\footnotetext{
* Correspondence: ivanhenriquezlopez@me.com

${ }^{1}$ Department of Radiation Oncology, University Hospital of Sant Joan. Institute d'Investigació Sanitaria Pere Virgili (IISPV), Reus, Tarragona, Spain ${ }^{4}$ Department of Radiation Oncology, Radiation Oncology Medical Institute, IMOR, Barcelona, Spain

Full list of author information is available at the end of the article
}

Surgery, cryotherapy and brachytherapy are among the most frequently used local salvage treatment options with different degrees of success [2-11]. At the present time, there is no consensus about what the optimal salvage treatment should be in patients who are presumed to have exclusive local recurrence after radiation therapy.

BT as a salvage treatment modality seems to have a potential benefit in patients with local relapse after radiotherapy in other solid tumors [12].

The role of ADT in combination with salvage BT in prostate local recurrence is uncertain because the different 
studies available comprise a limited and inhomogeneous patient sample $[5,6,8-11,13]$.

Herein, we present the outcome and toxicity in a cohort of patients with locally recurrent prostate cancer treated with salvage BT. Potential predictors of biochemical failure and toxicity after salvage BT were also identified.

\section{Materials and methods}

From January 1993 to July 2007, 56 consecutively patients with biochemical failure by ASTRO or Phoenix definitions [14,15], and local biopsy-proven recurrence after radiation therapy were included in this pooledanalysis study. Eligibility criteria included a negative evaluation of systemic disease, a good urinary and bowel function and a life expectancy more than 5 years.

All information from these patients was collected via retrospective chart review. The prostate biopsy specimen was review by a pathologist of each institution who was familiar with radiation effects on the prostate to avoid false-positive results.

Forty-six patients (82\%) were primarily treated with (EBRT) to a median dose of 72 Gy (range, 64 Gy 78 Gy) and 10 patients (18\%) were initially treated with LDR-BT. LDR-patients had received pre-planned $\mathrm{D}_{100}$ doses of at least 145 Gy. There was insufficient information of the postimplant $\mathrm{D}_{90}$ values.

Other salvage options such as cryotherapy or radical prostatectomy were discussed as well but were refused by the patients. Written informed consent was obtained from the patients for participation in this retrospective review, which was approved by the Institutional Review Boards of the participating institutions.

\section{Salvage treatment}

Patients were excluded for salvage brachytherapy if they did not meet all of the following criteria: Qmax $>15 \mathrm{ml} / \mathrm{seg}$, and a prostate volume $<50 \mathrm{~cm}^{3}$.

A total of 19 (34\%) patients were treated with salvage ${ }^{192} \mathrm{Ir}$ HDR-BT and 37 (66\%) patients with salvage ${ }^{125}$ I LDR-BT.

The technique for both permanent and temporal implant followed the local treatment policy of each centre. The characteristics of the patients are shown in Table 1.

The total dose to be administered with salvage brachytherapy, either ${ }^{125}$ I LDR-BT or ${ }^{192}$ Ir HDR-BT is yet to be determined. We use the linear quadratic formulation for dose equivalence. Assuming that the $\alpha / \beta$ ratio for prostate is about $1.5 \mathrm{~Gy}$ [16], the rationale of this study was to use an HDR-BT regimen that provided a $\mathrm{BED}_{2}$ of at least 50 Gy EQD2 [17]. Table 2 shows the different HDR dose levels with the corresponding BEDs values using a $\alpha / \beta$ ratio of 1.5 and 3.0. Patients salvaged with LDR-BT were treated with the same dose recommended by the guidelines for primary tumor in the same setting than other authors have reported.

Although there is no specific guideline for reirradiation volumes, we followed the GEC-ESTRO recommendations for volume definition and dose prescription [18]. The CTV for HDR-BT included the prostate and seminal vesicles (if appropriate). The CTV for LDR-BT was the prostate only. The following parameters were recommended for all investigators: V100 $\geq 95 \%$ of the CTV; D $90>100 \%$ of the prescribed dose. Post-implantation CT dosimetry were recommended to be performed 4 to 6 weeks after BT for those patients treated with LDR-BT according to the recommendations of the AAPM [19].

The mean prescription dose for salvage ${ }^{125}$ I LDR-BT was $145 \mathrm{~Gy}$ (range, 120 - $160 \mathrm{~Gy}$ ). The mean prescription dose for ${ }^{192}$ Ir HDR-BT was 50.5 Gy (range, 17 - 39 Gy), with a mean dose per fraction of 6.2 Gy (median, 5.25 Gy per fraction) in 1-3 implants (range, 1-4 fractions). The mean number of plastic tubes used per implant was 13 (range, $9-18$ ).

\section{Androgen deprivation therapy}

At the time of recurrence, neoadjuvant and adjuvant ADT was used in 15 patients (HDR-BT 9 pts; LDR-BT 6 pts) during 3 and 36 months. Only three patients received 36 months hormonal therapy. The follow-up of these three patients from the end of hormonal treatment was 24,25 and 36 months, respectively.

\section{Statistical analysis}

Cancer control outcomes were calculated using the actuarial method of Kaplan and Meier [20]. BF was defined following the ASTRO or the Phoenix definition $[14,15]$. Outcomes measured include FFbF and disease-free survival (DFS). DFS was measured from the date of BT salvage until the occurrence of one of the following events, whichever occurred first: BF, local or distant disease, start of any treatment for prostate cancer or any cause of death. Other outcomes evaluated included DMFS, CSS and OS.

\section{Univariate and multivariate analysis}

For this cohort of patients, univariate and multivariate were performed to identify potential predictors of biochemical control, survival and toxicity following salvage BT. The association of the different variables analyzed with BF and toxicity (initial age, tumor, PSA, and Gleason score, D'Amico risk group at initial treatment [21], initial EBRT dose, nadir PSA post-initial treatment, time to nadir PSA post-initial treatment, interval to relapse after initial treatment, ADT and PSA at salvage, salvage BT dose, and post-salvage PSA nadir) was evaluated with the Chi-square test and their association with outcome measures was determined with the log-rank test and the Cox regression 
Table 1 Initial and salvage patient characteristics

\begin{tabular}{|c|c|c|}
\hline Characteristics & $\begin{array}{l}\text { At initial } \\
\text { presentation }\end{array}$ & At salvage \\
\hline \multirow[t]{2}{*}{ Age (years) } & Mean 60 & Mean 65 \\
\hline & Range 50 - 77 & Range 60 - 80 \\
\hline \multirow[t]{2}{*}{ KPS } & Mean 80 & Mean 80 \\
\hline & Range 70 - 90 & Range 70 - 90 \\
\hline \multirow[t]{3}{*}{ PSA ng/ml } & Mean 17.3 & Mean 5 \\
\hline & Median 10.7 & Median 3.7 \\
\hline & Range 4 - 121 & Range 1.1 - 30 \\
\hline PSA ng/ml & Patients (\%) & Patients (\%) \\
\hline$<10 \mathrm{ng} / \mathrm{ml}$ & $26(46 \%)$ & 51 (91\%) \\
\hline $10-20 \mathrm{ng} / \mathrm{ml}$ & $18(32 \%)$ & $4(7 \%)$ \\
\hline$>20 \mathrm{ng} / \mathrm{ml}$ & $12(22 \%)$ & $1(2 \%)$ \\
\hline Gleason score & Patients (\%) & Patients (\%) \\
\hline$\leq 3+3$ & $37(66 \%)$ & $9(16 \%)$ \\
\hline $3+4 / 4+3$ & $16(29 \%)$ & $14(25 \%)$ \\
\hline$\geq 4+4$ & $3(5 \%)$ & $8(14 \%)$ \\
\hline Unavailable & & $25(45 \%)$ \\
\hline T stage & Patients (\%) & Patients (\%) \\
\hline T1c & $23(41 \%)$ & \\
\hline $\mathrm{T} 2$ & $26(46 \%)$ & \\
\hline $\mathrm{T} 3$ & 7 (13\%) & \\
\hline
\end{tabular}

Unknown

Recurrent

D'Amico risk group

Low

Intermediate

High

Unknown

Radiation treatment

EBRT

$<72 \mathrm{~Gy}$

$>72$ Gy

LDR-BQT

HDR-BQT

Time to biochemical relapse

(ASTRO/Phoenix definition)

$<24$ months

$>24$ months

Androgen deprivation therapy

Yes

No
$56(100 \%)$

Patients (\%) Patients (\%)

$24(43 \%)$

$16(28.5 \%)$

$16(28.5 \%)$

Patients (\%) Patients (\%)

$46(82 . \%)$

$24(43 \%)$

$22(39 \%)$

$10(18 \%)$

$37(66 \%)$

$19(34 \%)$

Patients Patients

ASTRO PHOENIX

$6(11 \%) \quad 4(7 \%)$

$50(89 \%) \quad 52(93 \%)$

Patients (\%)

Patients (\%)

$26(46 \%)$

$15(27 \%)$

$41(73 \%)$
Table 1 Initial and salvage patient characteristics

(Continued)

\begin{tabular}{lll}
\hline Time to nadir post-RT/BQT & & \\
$\leq 6$ months & $15(26.8 \%)$ & \\
$6-12$ months & $7(12.5 \%)$ & \\
$>12$ months & $34(60.7 \%)$ & \\
Nadir PSA post-radiation & Mean $0.6 \mathrm{ng} / \mathrm{ml}$ & Mean $0,5 \mathrm{ng} / \mathrm{ml}$ \\
& Median $0.5 \mathrm{ng} / \mathrm{ml}$ & Median $0.16 \mathrm{ng} / \mathrm{ml}$ \\
& Range $0.001-$ & Range $0.001-$ \\
& $3 \mathrm{ng} / \mathrm{ml}$ & $2.9 \mathrm{ng} / \mathrm{ml}$
\end{tabular}

$L D R-B Q T=$ low dose rate brachytherapy; $H D R-B Q T=$ high dose rate brachytherapy.

method. Two-sided $\mathrm{p}$ values of less than 0.05 were considered statistically significant.

\section{Follow-up}

Patients were followed-up by the Radiation Oncology staff of the participating Institutions every 6 months, for the first 4 years, and on a yearly basis thereafter. Toxicities were recorded and graded using CTCv3.0 [22].

\section{Results}

Outcomes

With a median follow-up of 48 months (range, 25 109), the 5-year actuarial FFbF was $77 \%$ (Figure 1). The 5 -year OS rate was $70 \%$.

Insufficient data were available to assess the IPSS before and after treatment.

On univariate analysis, the factors associated with biochemical failure were psa at salvage $>10 \mathrm{ng} / \mathrm{ml}(\mathrm{p}=0.004$, OR 16.4, 95\% CI 1.82-147.7), interval to relapse after initial treatment $<24$ months $(\mathrm{p}=0.004$, OR $16.4,95 \%$ CI 1.82 -

Table 2 Characteristics of salvage BT-HDR dose levels and total BED

\begin{tabular}{|c|c|c|c|c|}
\hline \multirow{2}{*}{$\begin{array}{c}\text { HDR-BT } \\
\text { doses }\end{array}$} & \multirow{2}{*}{$\begin{array}{c}\text { BED } \\
(\alpha / \beta=1.5)\end{array}$} & \multirow{2}{*}{$\begin{array}{c}\text { BED } \\
(\alpha / \beta=3)\end{array}$} & \multicolumn{2}{|c|}{ Total BED 2 Gy } \\
\hline & & & $\alpha / \beta=1.5 \mathrm{~Gy}$ & $3 \mathrm{~Gy}$ \\
\hline 8.5 Gy $\times 2$ & 125 & 65 & 52 & 39 \\
\hline $6 \mathrm{~Gy} \times 4$ & 132 & 72 & 55 & 43 \\
\hline $9 \mathrm{~Gy} \times 2$ & 140 & 72 & 59 & 43 \\
\hline $9.5 \mathrm{~Gy} \times 2$ & 154 & 79 & 65 & 48 \\
\hline $6 \mathrm{~Gy} \times 5$ & 165 & 90 & 69 & 54 \\
\hline $8.5 \mathrm{~Gy} \times 4$ & 227 & 130 & 95 & 78 \\
\hline 9 Gy $\times 4$ & 279 & 144 & 116 & 86 \\
\hline 10.5 Gy $\times 3$ & 280 & 140 & 117 & 84 \\
\hline $9.5 \mathrm{~Gy} \times 4$ & 308 & 158 & 119 & 95 \\
\hline $13 \mathrm{~Gy} \times 3$ & 419 & 208 & 240 & 206 \\
\hline
\end{tabular}

$H D R-B T=$ high dose rate brachytherapy; $B E D=$ biological equivalent doses; $\alpha / \beta=$ alfa/beta; $B E D_{2} G y=$ biological equivalent doses at 2 Gy per fraction. 


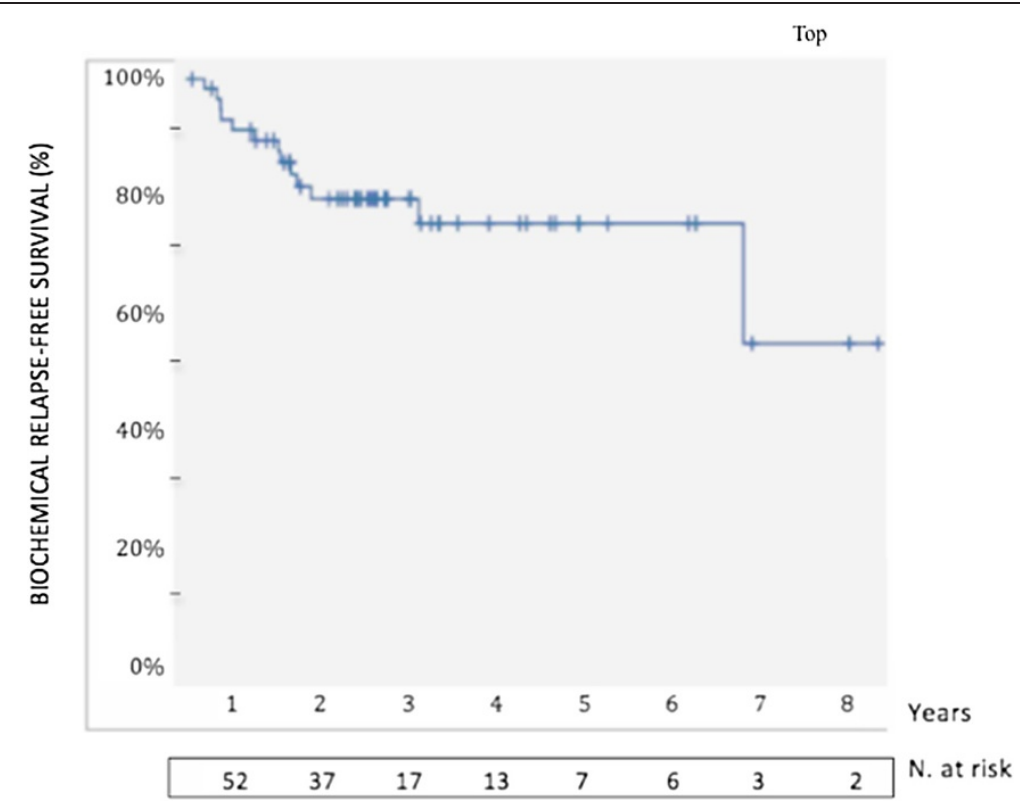

Figure 1 Kaplan-Meier freedom from biochemical failure post-salvage brachytherapy with 5-year estimates.

147.7), and salvage HDR-BT doses $\mathrm{BED}_{2}$ Gy level $\leq 227$ Gy $(\mathrm{p}=0.012$, OR $18,95 \%$ CI 1.75-184.8). Nadir PSA $>1 \mathrm{ng} / \mathrm{ml}$ at relapse was of borderline significance in predicting $\mathrm{BF}$ ( $\mathrm{p}=0.087$, OR 4.35; 95\% CI, 0.73-25.6).

On Cox multivariate analysis, PSA at relapse $>10 \mathrm{ng} / \mathrm{ml}$ $(\mathrm{p}=0.043$, OR $0.181,95 \%$ CI 0.03-0.84), and time to relapse $<24$ months $(\mathrm{p}=0.031$, OR 0.160 , 95\% CI 0.057 0.571 ) was strongly associated with biochemical failure.

The factors significantly associated with Grade $\geq 2$ urinary toxicity were androgen deprivation therapy at relapse, and HDR-BT at salvage $\left(\mathrm{BED}_{2}\right.$ Gy level $\left.\geq 227\right)$ (Table 3). No factor predictive of rectal toxicity was found.

At the time of this analysis, only one patient had died of prostate cancer at 25 months from salvage BT.

\section{Toxicity}

\section{HDR-BT urinary toxicity}

Three out of the 19 patients did not develop any urinary toxicity. Four patients (21\%) had Grade 3 toxicity requiring medical support or intervention for symptom relief

Table 3 Multivariate analysis of factors that may influence Grade $\geq 2$ urinary toxicity

\begin{tabular}{lll}
\hline Factor & OR $(\mathbf{9 5} \% \mathrm{Cl})$ & p value \\
\hline ADT at relapse (yes vs. not) & $0.494(0.245-0.997)$ & 0.049 \\
HDR-BT at salvage & $0.459(0.242-0.870)$ & 0.017 \\
$\mathrm{BED}_{2}$ Gy level $\geq 227$ vs & & \\
$\mathrm{BED}_{2}$ Gy level $<227$ & & \\
\hline
\end{tabular}

$A D T=$ androgen deprivation therapy; $O R=$ odd ratio; $H D R-B T=$ high dose rate brachytherapy; $B E D_{2}$ Gy $=$ biological equivalent doses. (urethral stricture that interfered in daily activities requiring periodical dilations $n=4$ ). There were no cases of Grade 4 . or greater urinary toxicity.

\section{LDR-BT urinary toxicity}

Eight out of 37 patients did not develop any urinary toxicity. Nine patients (24\%) had Grade 3 toxicity (bladder sphincter spasms requiring narcotics, $\mathrm{n}=3$; obstructive uropathy requiring TURP after 36 months from salvage therapy, $\mathrm{n}=5$ ). There were no cases of Grade 4 or greater urinary toxicity.

\section{$H D R-B T$ rectal toxicity}

Thirteen of 19 patients did not develop rectal toxicity. One patient (2\%) developed a Grade 3 rectal event consisting of persistent rectal bleeding requiring argon laser therapy with complete resolution.

\section{LDR-BT rectal toxicity}

Nineteen out of 37 patients did not develop any rectal toxicity. One patient $(2.7 \%)$ had Grade 4 rectal toxicity that consisted of a prostatorectal fistula. This patient required colostomy 24 months after salvage therapy. There were no cases of Grade 3 or 5 rectal toxicities.

The information available to assess the rates of erectile dysfunction after salvage BT was not complete enough to report on this item.

\section{Discussion}

The present study represents, to the best of our knowledge, the largest series of salvage BT ever published. 
Salvage BT resulted in a 5-year actuarial $\mathrm{FFbF}$ of $77 \%$ with a corresponding 5-year OS and a CSS rate of 70\% and $97 \%$, respectively. These results are comparable with other prior reports on salvage BT (5,6,8-11).

The evidence published at literature of salvage BT varies according to patient and disease-related characteristics and suggests a wide range of outcomes and toxicities. For properly selected patients with local failure after definitive RT, salvage BT can provide longterm disease control comparable with other salvage modalities.

Even the mid-term follow-up of this study is limited, our study of salvage BT found a high 5-year biochemical control rate and it provides durable disease control in a substantial percentage of patients after local recurrence of prostate cancer despite previous definitive RT.

Biochemical failure after primary radiation in localized prostate cancer occurs after 60 months, and therefore a longer follow-up is desirable to analyze how the impact of treatment should be. However, in a salvage treatment (surgery, cryotherapy, brachytherapy), the oncology situation is different probably because of tumor cell becomes more resistant to salvage treatment and therefore many of $\mathrm{BF}$ is expected to be in the first 5-year after treatment. This situation is frequently to be observed in other solid tumors.

Chen [9], in a salvage HDR-BT study of 52 patients had a BF of $49 \%$ at 5 -year. Most of these failures occur before 48 months after treatment. A study with 37 patients from Mount Sinai Medical Center [11] examined the role of salvage LDRB for local failure after prostate radiation therapy. The 5-year BF reported was 35.5\%. Only a $11 \%$ more of BF was observed at 10 -year.

In addition, the mean of follow-up of most relevant salvage brachytherapy series published from 1999 is 52 months (30 - 86 months). The majority of BF of the series are reported at 5 -year $[3,4,6,8,9]$, except one author [11], at 10-year (Table 4).

Our-study revealed that $23 \%$ of BF occur in the first 5 -year, and hormonal treatment at relapse did not have any influence on $\mathrm{BF}(\mathrm{p}=0.126$, OR 0.298 , 95CI $0.063-1.4)$.

At this moment, if there is a suspicious of failure by a rising of PSA after radiation therapy, physical exam with rectal examination, magnetic resonance imaging, bone CT-scan and biopsy-proven histology are strongly recommended before a patient could be offered a salvage treatment. Even, there is an estimation of $70 \%$ of relapse are localized at prostate, these biological, clinical and radiological methods are insufficient to demonstrate whether the relapse is local or not. However, in the last years, some prognostic factors have been identified at diagnosis, at initial treatment and at relapse which are associated with lower rates of PSA recurrence by 5 years after any of the salvage local therapies [1]. These factors should be taken into account because they may help to identify the best candidate to offer salvage brachytherapy, as it is suggest by other authors [1].

The consensus of ASTRO (1997) and Phoenix (2005) clearly defined PSA failure after radiation therapy $[14,15]$. Actually, it is not possible to make definitive statements of PSA failure after salvage brachytherapy because of wide variety of PSA definition reported at literature [3-11]. In our study, the Phoenix criteria were used for relapse after salvage brachytherapy as it was considered by some recent publications [7,9-11].

A number of predictive factors have been related with the risk of subsequent failure and toxicity in patients with local failure treated for salvage [1,9,11,23-26]. To facilitate a better patient selection for salvage BT, our study revealed that the disease-free interval after initial definitive RT, the prior salvage PSA, and salvage HDR$\mathrm{BT}$ doses $\left(\mathrm{BED}_{2}\right.$ Gy level $\left.\leq 227\right)$ were each of significance in predicting biochemical control after salvage BT. Also, nadir PSA $>1 \mathrm{ng} / \mathrm{ml}$ after salvage BT was of borderline significance $(\mathrm{p}=0.087)$.

A larger interval of disease-free after initial definitive radiation therapy may suggest local rather than regional/or distant disease recurrence. Chen [9] found a borderline significance in predicting biochemical failure in those patients with a prolonged disease-free interval after initial definitive radiation therapy.

Presalvage PSA is an important predictor of outcome for salvage brachytherapy.

Burri [11] showed a trend for increased freedom from BF in patients with low PSA at the time of salvage LDR. In the postoperative RT literature, earlier salvage external beam RT, results in higher progression-free survival when the presalvage PSA is lower [24]. Similar to other modalities, salvage RP is more effective when the preoperative PSA is lower [23,27].

Although elevated Gleason score [23], extended interval from first recurrence to time to earlier salvage RT [24] and percent positive cores biopsies $[9,26]$ have been found to be a predictor of $\mathrm{BF}$ and disease progression, in our salvage BT study we did not find any correlation.

However, only a prospective randomized trial can make definitive statements in PSA failure and prognostic factors after salvage brachytherapy.

The occurrence of relevant treatment adverse effects combined with otherwise good results in terms of cancer control have led to a growing interest in evaluating the impact of treatment on quality of life (QoL).

Surgery, radiation therapy or brachytherapy alone or associated to hormonal treatment is an effective treatment but caused urinary, bowel, or sexual dysfunction with different frequency, duration, and severity. Radical 
Table 4 Salvage brachytherapy series after local failure of radiation therapy for prostate cancer

\begin{tabular}{|c|c|c|c|c|c|c|}
\hline Study, year & Salvage brachytherapy doses & $\mathbf{N}$ & Pre-salvage PSA (ng/ml) & Median f/u (mo) & Outcome & Grade $3 / 4$ toxicity \\
\hline \multirow[t]{2}{*}{ Grado et al., 1999 [4] } & LDR 145 Gy & 49 & 5.6 & 64 & $34 \% 5-y b^{2} F^{a}$ & $16 \%$ \\
\hline & & & & & $56 \% 5-y$ bDFS & \\
\hline \multirow[t]{2}{*}{ Beyer et al., 1999 [3] } & LDR 120 Gy ${ }^{125}$ & 17 & 2.2 & 62 & $53 \% 5-y F_{F S R}$ & $N R$ \\
\hline & $90 \mathrm{~Gy}{ }^{103} \mathrm{P}$ & & & & & \\
\hline Wong et al., 2006 [5] & LDR 126 Gy & 17 & 4.7 & 44 & $75 \%$ 4-y FfbF & $47 \%$ \\
\hline Allen et al., 2007 [6] & LDR $97 \mathrm{~Gy}^{\mathrm{d}}$ & 12 & 3.8 & 45 & $63 \% 5-y \mathrm{FfbF}^{\mathrm{c}}$ & $0 \%$ \\
\hline Chen et al., 2013 [9] & HDR 36 Gy & 52 & 9.3 & 59.6 & $51 \% 5-y \mathrm{FfbF}^{\mathrm{e}}$ & $2 \%$ \\
\hline Nguyen et al., 2007 [7] & LDR 137 Gy $^{f}$ & 25 & 9.46 & 46 & $70 \%$ 4-y FfbF & $30 \%$ \\
\hline Lee et al., 2008 [8] & LDR $90 \mathrm{~Gy}^{\mathrm{g}}$ & 21 & 3.8 & 36 & $38 \% 5-y \mathrm{FfbF}^{\mathrm{c}}$ & $0 \%$ \\
\hline Aaronson et al., 2009 [10] & LDR 144 Gy & 24 & 3.4 & 30 & $89 \% 3-y \mathrm{FfbF}^{\mathrm{e}}$ & $4 \%$ \\
\hline \multirow[t]{2}{*}{ Burri et al., 2010 [11] } & LDR 135 Gy ${ }^{125}$ | & 37 & 5.6 & 86 & 65\% 5-y FFbF & $11 \%$ \\
\hline & $110 \mathrm{~Gy}{ }^{103} \mathrm{p}$ & & & & $54 \% 10-y \mathrm{FfbF}^{\mathrm{e}}$ & \\
\hline \multirow[t]{5}{*}{ Current series, 2013} & HDR (BED 2 Gy $) 125-419$ Gy & 56 & 5 & 48 & 77\% 5-y FFbF & HDR GU/GI \\
\hline & & & & & & G3.......21\%/2\% \\
\hline & LDR 145 Gy & & & & & LDR GU/GI \\
\hline & & & & & & G3....24\%/0\% \\
\hline & & & & & & G4.....0\%/ 2.7\% \\
\hline
\end{tabular}

$L D R=$ low dose rate; $H D R=$ high dose rate; $b D F S=$ biochemical disease-free survival; $F F S R=$ freedom from second relapse; $N R=$ not reported; $G U=$ genitourinary; GI = gastrointestinal; $G 3=$ grade $3 ; G 4$ = grade 4.

${ }^{\text {a}}$ Failure defined as two PSA rises above nadir.

${ }^{b}$ Nadir psa $<0.5 \mathrm{ng} / \mathrm{ml}$.

'Failure defined as ASTRO definition.

${ }^{\mathrm{d}}$ Median dose.

'Failure defined as Phoenix definition.

${ }^{\mathrm{f}}$ Median minimum peripheral dose.

${ }^{\mathrm{g}}$ Minimum peripheral dose.

prostatectomy caused urinary incontinence and sexual dysfunction but improved preexisting urinary irritativeobstructive symptoms. External radiotherapy and brachytherapy caused urinary irritative-obstructive adverse effects and some sexual dysfunction. External radiotherapy also caused bowel adverse effects [28,29].

Although salvage treatment (surgery, cryotherapy, brachytherapy) is associated with reasonable cancer control outcomes, sexual, rectal and urinary dysfunction is the mainstay limitations for preserving quality of life (QoL). Actually, there is not prospectively data available in QoL in patients treated with salvage treatment. Most of data reported are based on functional outcomes instead of validated QoL instruments [10,11].

In our study, there were some exclusion criteria based on Qmax and prostate volume, and also, some technical recommendations and a quality parameters of brachytherapy treatment based on GEC-ESTRO guidelines for volume definition and dose prescription. Although these recommendations are insufficient, they are useful to minimize toxicity in urethra, rectal, bladder and sexual function from brachytherapy treatment. While we were unable to document the IPPS on follow-up, at baseline these men had generally good urinary function before BT. The lack of patient questionnaires make this observation circumspect.

Nowadays, there is a strong recommendation to use QoL instruments in future trials of salvage brachytherapy.

Urinary toxicity profile is very important in patients who undergone salvage brachytherapy.

Recently, Chen [9], reported in 52 patients with local recurrence after radiation therapy treated with salvage HDR-BT an acute and late grade $3 \mathrm{GU}$ toxicities in only $2 \%$ and $2 \%$, respectively. In this study, all patients received the same salvage treatment with the same total HDT-BT dose and fractionation. The authors did not reported any Grade 4 or 5 GU toxicity. The explanation of this low GU toxicity may be a selection of patients with low urinary toxicity at baseline (even the authors did not reported any based-QoL instruments such as IPSS), and the homogeneous procedure applied in technique, dose and fractionation with HDR-BT. In addition, the urethralsparing technique included [30] may help limit the rate of urethral stricture. This is the lowest urinary toxicity published with this technique when it is compare with other salvage brachytherapy series $[1,4,5,7,10,11,25]$. 
Table 5 Most relevant average toxicities of different salvage techniques

\begin{tabular}{ccccc}
\hline Salvage technique & Incontinence & $\begin{array}{c}\text { Rectal } \\
\text { injury }\end{array}$ & $\begin{array}{c}\text { Bladder neck } \\
\text { stricture }\end{array}$ & Fistula \\
\hline $\begin{array}{c}\text { Prostatectomy } \\
{[23,27]}\end{array}$ & $41 \%$ & $4.7 \%$ & $24 \%$ & \\
$\begin{array}{c}\text { Cryotherapy } \\
{[26,31,32]}\end{array}$ & $36 \%$ & & $17 \%$ & $2.6 \%$ \\
$\begin{array}{c}\text { Brachytherapy } \\
{[1,3-5,7-11]}\end{array}$ & $6 \%$ & $5.6 \%$ & $17 \%$ & $3.4 \%$ \\
\hline
\end{tabular}

In our study, late grade $3 \mathrm{GU}$ toxicity was observed in $21 \%$ and $24 \%$ in patients salvaged either with HDR or LDR, respectively. Several factors may explain this GU toxicity, such as, different techniques of brachytherapy, doses and fractionations. Also, we did not quantified any qualified urinary instruments (IPSS) that helped to select a patient with a good urinary function before salvage BT. All these factors may contribute to have a high urinary toxicity.

Even, the GU toxicity in our study are high, the observed rate averaged those described in former reports $[1,4,5,7,10,11,25]$. The mean average urinary toxicity from salvage BT series are incontinence in $6 \%$ and urethral stricture in $17 \%$, respectively. In addition, when we compared with other salvage modalities, the urinary toxicity profile of our study is acceptable. For example, salvage prostatectomy has an associated incontinence rate of $45 \%$ (range:0\%-80\%) and salvage cryoablation can result in incontinence rates ranging from $4.7 \%$ to $95 \%$ (Table 5).

A better selection of presalvage BT patients with good urinary function (IPSS $<8$ or AUA $<10$ scores), and the use of an urethral-sparing technique [30] may help to decrease urinary morbidity.

The results of the present study are far from conclusive due to the wide variability of patients, treatment characteristics regarding BT type, doses and ADT schedule. The retrospective nature of the study and it's a potential for selection bias may preclude the identification of some patient and treatment-related factors that might influence on outcomes or toxicities.

Nonetheless, even these limitations, we still demonstrated a consistent disease control in a majority of patients. In addition, we identified some potential predicting factors for local control and urinary toxicity that are in line with predictors identified for other salvage modalities. However, we must be cautious to further investigate these predicting factors of outcome and toxicity in prospective trials.

Prospective multi-institutional trials (Radiation Therapy Oncology Group 0526) and the Spanish phase II trial (Anabraq) of salvage BT with or without ADT are currently open to accrual to address these concerns.

\section{Conclusions}

This pooled-analysis study has demonstrated that BT, with careful selection criteria is a feasible salvage treatment after EBRT failure. Even, we identified some predictors of biochemical control and urinary toxicity that may help patient selection for prostate salvage BT, further investigation is recommended in future trials.

\section{Abbreviations \\ BT: Brachytherapy; pts: Patients; HDR-BT: High-dose-rate brachytherapy; LDR-BT: Low-dose-rate brachytherapy; $\mathrm{BED}_{2}$ Gy: Biological equivalent doses; ADT: Androgen deprivation therapy; FFbF: Freedom from biochemical failure; OS: Overall survival; GU: Genitourinary; GI: Gastrointestinal; CTCv3.0: Common Terminology Criteria for Adverse Events; a/ $\beta$ : alpha/beta; CTV: Clinical target volume; DFS: Disease-free survival; DMFS: Distant metastasis free survival; CSS: Cause-specific survival; PSA: Prostate antigen specific; Gy: Gray; EBRT: External beam radiotherapy.}

\section{Competing interest}

The authors declare that they have no competing interest.

\section{Authors' contributions}

$I H, A P, G S, B G$ designed the study and the analysis. JP, CG, RMM collected de clinical and dosimetric data. AT, OA, AH contributed to interpretation of data. All authors have given final approval of the manuscript.

\section{Authors' information}

Presented in part at the ESTRO Congress 2010, Barcelona, Spain.

\section{Acknowledgments}

The authors would like to thank Pilar Hernandez, Institut d'Investigació Sanitaria Pere Virgili (IISPV) for support with statistical management.

\section{Author details}

'Department of Radiation Oncology, University Hospital of Sant Joan. Institute d'Investigació Sanitaria Pere Virgili (IISPV), Reus, Tarragona, Spain. ${ }^{2}$ Department of Radiation Oncology, Hospital de la Santa Creu i Sant Pau, Barcelona, Spain. ${ }^{3}$ Department of Radiation Oncology, Brachytherapy Unit, Hospital Ramón y Cajal, Madrid, Spain. ${ }^{4}$ Department of Radiation Oncology, Radiation Oncology Medical Institute, IMOR, Barcelona, Spain. ${ }^{5}$ Department of Radiation Oncology, Brachytherapy Unit, Institut Catalâ d'Oncologia, Barcelona, Spain. ${ }^{6}$ Department of Radiation Oncology, Virgilio Galvis Ramirez Cancer Centre, Bucaramanga, Colombia. 'Department of Radiation Oncology, University Clinic of Navarra, CUN, Pamplona, Spain. ${ }^{8}$ Department of Radiation Oncology, University Hospital Politècnic La Fe, Valencia, Spain.

Received: 13 September 2013 Accepted: 15 April 2014 Published: 30 April 2014

\section{References}

1. Nguyen PL, D'Amico AV, Lee AK, Suh WW: Patient selection, cancer control, and complications after salvage local therapy for postradiation prostate-specific antigen failure: a systematic review of the literature. Cancer 2007, 110:1417-1428.

2. Cox JM, Busby E: Salvage therapy for prostate cancer recurrence after radiation therapy. Curr Urol Rep 2009, 10:199-205.

3. Beyer DC: Permanent brachytherapy as salvage treatment for recurrent prostate cancer. Urology 1999, 54:880-883.

4. Grado GL, Collins JM, Kriegshauser JS, Balch CS, Grado MM, Swanson GP: Salvage brachytherapy for localized prostate cancer after radiotherapy failure. Urology 1999, 53:2-10.

5. Wong WW, Buskirk SJ, Schild SE, Prussak KA, Davis BJ: Combined prostate brachytherapy and short-term androgen deprivation therapy as salvage therapy for locally recurrent prostate cancer after external beam irradiation. J Urol 2006, 176:2020-2024.

6. Allen GW, Howard AR, Jarrard DF, Ritter MA: Management of prostate cancer recurrences after radiation therapy-brachytherapy as a salvage option. Cancer 2007, 110:1405-1416. 
7. Nguyen PL, Chen MH, D'Amico AV, Tempany CM, Steele GS, Albert M: Magnetic resonance image-guided salvage brachytherapy after radiation in selected men who initially presented with favourable-risk prostate cancer: a prospective phase 2 study. Cancer 2007, 110:1485-1492.

8. Lee HK, Adams MT, Motta J: Salvage prostate brachytherapy for localized prostate cancer failure after external beam radiation therapy. Brachytherapy 2008, 7:17-21.

9. Chen CP, Weinberg V, Shinohara K, Roach M 3rd, Nash M, Gottschalk A, Chang AJ, Hsu IC: Salvage HDR brachytherapy for recurrent prostate cancer after previous definitive radiation therapy: 5-year outcomes. Int J Radiat Oncol Biol Phys 2013, 86:324-329.

10. Aaronson DS, Yamasaki I, Gottschalk A, Speight J, Hsu IC, Pickett B, Roach M 3rd, Shinohara K: Salvage permanent perineal radioactive-seed implantation for treating recurrence of localized prostate adenocarcinoma after external beam radiotherapy. BJU Int 2009, 104:600-604.

11. Burri RJ, Stone NN, Unger P, Stock RG: Long-term outcome and toxicity of salvage brachytherapy for local failure after initial radiotherapy for prostate cancer. Int J Radiat Oncol Biol Phys 2010, 77:1338-1344.

12. Guix B, Lejarcegui JA, Tello Jl, Zanón G, Henríquez I, Finestres F, Martinez A Fernandez-lbiza J, Quinzaños L, Palombo P, Encinas X, Guix I: Exeresis and brachytherapy as salvage treatment for local recurrence after conservative treatment for breast cancer: results of a ten-year pilot study. Int J Radiat Oncol Biol Phys 2010, 78:804-810.

13. Kumar S, Shelley M, Harrison C, Coles B, Wilt TJ, Mason MD: Neo-adjuvant and adjuvant hormone therapy for localised and locally advanced prostate cancer [Review], The Cochrane Library 2007; 2006. Available on line at http:// www.thecochranelibrary.com.

14. American Society for Therapeutic Radiology and Oncology Consensus Panel: Consensus statement: guidelines for PSA following radiation therapy. Int J Radiat Oncol Biol Phys 1997, 37:1035-1041.

15. Roach M 3rd, Hanks G, Thames H Jr, Schellhammer P, Shipley WU, Sokol GH, Sandler H: Defining biochemical failure following radiotherapy with or without androgen deprivation therapy in men with clinically localized prostate cancer: recommendations of the RTOG-ASTRO Phoenix. Int J Radiat Oncol Biol Phys 2006, 65:965-974.

16. King CR, Fowler JF: A simple analytic derivation suggests that prostate cancer a/b ratio is low. Int J Radiat Oncol Biol Phys 2001, 51:213-214.

17. Nag S, Martinez-Monge R, Copeland LJ, Vacarello L, Lewandowski GS: Perineal template intersticial brachytherapy salvage for recurrent endometrial adenocarcinoma metastatic to the vagina. Gynecol Oncol 1997, 66:16-19.

18. Kovács G, Pötter R, Loch T, Hammer J, Kolkman-Deurloo IK, de la Rosette JJ, Bertermann H: GEC/ESTRO-EAU recommendations on temporary brachytherapy using stepping sources for localised prostate cancer. Radiother Oncol 2005, 274:137-148.

19. Nath R, Bice WS, Butler WM, Chen Z, Meigooni AS, Narayana V, Rivard MJ, $\mathrm{YU} \mathrm{J}$ : AAPM recommendations on dose prescription and reporting methods for permanent interstitial brachytherapy for prostate cancer: report of task group 137. Med Phys 2009, 36:5310-5322.

20. Kaplan EL, Meier P: Nonparametric estimation from incomplete observations. J Am Stat Assoc 1958, 53:457-481.

21. D'Amico AV, Whittington R, Malkowicz SB, Schultz D, Blank K, Broderick GA Tomaszewski JE, Renshaw AA, Kaplan I, Beard CJ, Wein A: Biochemical outcome after radical prostatectomy, external beam radiation therapy, or interstitial radiation therapy for clinically localized prostate cancer. JAMA 1998, 280:969-974.

22. Trotti A, Colevas AD, Setser A, Rusch V, Jaques D, Budach V, Langer C, Murphy B, Cumberlin R, Coleman CN, Rubin P: CTCAE v3.0: development of a comprehensive grading system for the adverse effects of cancer treatment. Sem Radiat Oncol 2003, 13:176-181.

23. Chade DC, Shariat SF, Cronin AM, Savage CJ, Karnes RJ, Blute ML, Briganti A, Montorsi F, van der Poel HG, Van Poppel H, Joniau S, Godoy G, Hurtado-Coll A, Gleave ME, Dall'Oglio M, Srougi M, Scardino PT, Eastham JA: Salvage radical prostatectomy for radiation-recurrent prostate cancer. a multi-institutional collaboration. Eur Urol 2011, 60:205-210.

24. Pound CR, Partin AW, Eisenberger MA, Chan DW, Pearson JD, Walsh PC: Natural history of progression after PSA elevation following radical prostatectomy. JAMA 1999, 281:1591-1597.

25. Tharp M, Hardacre M, Bennett R, Jones WT, Stuhldreher D, Vaught J: Prostate high-dose rate brachytherapy as salvage treatment of local failure after previous external or permanent seed irradiation for prostate cancer. Brachytherapy 2008, 7:231-236.

26. Levy DA, Li J, Jones JS: Disease burden predicts for favorable postsalvage cryoablation PSA. Urology 2010, 76:1157-1161.

27. Bianco FJ Jr, Scardino PT, Stephenson AJ, Diblasio CJ, Fearn PA, Eastham JA: Long-term oncologic results of salvage radical prostatectomy for locally recurrent prostate cancer after radiotherapy. Int J Radiat Oncol Biol Phys 2005, 62:448-453.

28. Pardo Y, Guedea F, Aguiló F, Fernández P, Macías V, Mariño A, Hervás A, Herruzo I, Ortiz MJ, Ponce De León J, Suárez JF, Boladeras A, Pont À, Ayala A, Sancho G, Martínez E, Alonso J, Ferrer M: Quality-of-life impact of primary treatments for localized prostate cancer in patients without hormonal treatment. J Clin Oncol 2010, 28:4687-4696.

29. Sanda MG, Dunn RL, Michalski J, Sandler HM, Northouse L, Hembroff L: Quality of life and satisfaction withoutcome among prostate-cancer survivors. N Engl J Med 2008, 358:1250-1261.

30. Cunha JA, Pouliot J, Weinberg V, Wang-Chesebro A, Roach M 3rd, Hsu IC: Urethra low-dose tunnels: validation of and class solution for generating urethra-sparing dose plans using inverse planning simulated annealing for prostate high-dose-rate brachytherapy. Brachytherapy 2012, 11:348-353.

31. Izawa JI, Madsen LT, Scott SM, Tran JP, McGuire EJ, Von Eschenbach AC, Pisters LL: Salvage cryosurgery for recurrent prostate cancer after radiotherapy: variables affecting patient outcome. J Clin Oncol 2002, 20:2664-2671.

32. Pisters LL, Rewcastle JC, Donnelly BJ, Lugnani FM, Katz AE, Jones JS: Salvage prostate cryoablation: initial results from the cryo on-line data registry. J Urol 2008, 180:559-563.

doi:10.1186/1748-717X-9-102

Cite this article as: Henríquez et al:: Salvage brachytherapy in prostate local recurrence after radiation therapy: predicting factors for control and toxicity. Radiation Oncology 2014 9:102.

\section{Submit your next manuscript to BioMed Central and take full advantage of:}

- Convenient online submission

- Thorough peer review

- No space constraints or color figure charges

- Immediate publication on acceptance

- Inclusion in PubMed, CAS, Scopus and Google Scholar

- Research which is freely available for redistribution 